\title{
Rock-Arch Instability Characteristics of the Sandstone Plate under Different Loading Conditions
}

\author{
Shuren Wang, ${ }^{1,2}$ Paul Hagan, ${ }^{3}$ Baowen $\mathrm{Hu},{ }^{4}$ Kanchana Gamage, ${ }^{3}$ \\ Cheng Yan, ${ }^{3}$ and Dianfu $\mathrm{Xu}^{1}$ \\ ${ }^{1}$ School of Civil Engineering and Mechanics, Yanshan University, Qinhuangdao 066004, China \\ ${ }^{2}$ Opening Laboratory for Deep Mine Construction, Henan Polytechnic University, Jiaozuo 454003, China \\ ${ }^{3}$ School of Mining Engineering, University of New South Wales, Sydney, NSW 2052, Australia \\ ${ }^{4}$ Civil and Environmental Engineering Institute, University of Science and Technology, Beijing 100083, China
}

Correspondence should be addressed to Shuren Wang; wangshurenysu@163.com

Received 23 February 2014; Accepted 21 April 2014; Published 19 May 2014

Academic Editor: Juan José del Coz Díaz

Copyright (C) 2014 Shuren Wang et al. This is an open access article distributed under the Creative Commons Attribution License, which permits unrestricted use, distribution, and reproduction in any medium, provided the original work is properly cited.

\begin{abstract}
Under the concentrated loading and the uniform loading, the tests on the brittle fracture and the hinged arching until the rock-arch instability of the sandstone plate were conducted using self-developed loading device, and the sensitivity of influent factors on the rock-arch failure was analyzed by numerical test based on the particle flow code (PFC). The results showed that sandstone plate instability presented four phases: small deformation elastic stage, brittle fracture arching stage, rock-arch bearing stage, and rockarch instability stage. Under the uniform loading, the maximum vertical force of the rock-arch instability was much higher than that under the concentrated loading condition, but the maximum lateral force was almost the same. The number of acoustic emission (AE) and its positioning results of the sandstone plate showed that the extent of the plate damage under the uniform loading was higher than that under the concentrated loading condition. The friction coefficient effect, size effect, loading rate effect, and the initial horizontal force effect on the rock-arch instability were analyzed by the $\mathrm{PFC}^{3 \mathrm{D}}$ numerical experiment.
\end{abstract}

\section{Introduction}

Over the past years in China, there are numerous shallow mined-out areas left due to the disordered mining by the private coal mines. It is of important theoretical and practical value for the roof stability evaluation and disaster forecasting to research on the deformation rupture, instability mechanism, and failure mode of the rock roof in the mined-out areas.

The studies on the instability of the rock roof in the mining field have been the main topic all the time for home and abroad scholars. For example, according to elastic thin plate theory, Wang et al. analyzed the fracture instability characteristics of the roof under different mining distances in the mining work face [1]. Wang et al. analyzed the rheological failure characteristics of the roof in the minedout areas through combining the thin plate and rheology theories [2-4]. Pan had conducted the analytical analysis of the variation trend of the bending moment, the deflection, and the shear force of the hard roof in the mining field [5]. These researches mentioned above are inclined to adopted traditional analytic methods to probe into the roof stability. There are also new theories and methods used in recent years. Zhao et al. utilized the catastrophe theory to set up vertical deformation model of the overlapping roof in the mined-out areas and put forward the criteria for evaluating the roof stability [6]. Wang et al. analyzed the chaos and stochastic resonance phenomenon produced in the roof during the evolutionary process of the rock beam deformation [7]. Meanwhile, some numerical computation methods were applied in discussing the mechanical response of rock plate or beam. Wang et al. analyzed the blast-induced stress wave propagation and the spalling damage in a rock plate by using the finite-difference code [8]. Nomikos et al. researched the mechanical response of the multijointed roof beams using two-dimensional distinct element code 
[9]. Bakun-Mazor et al. examined the arching mechanism of the blocky rock mass deformation after the underground tunnel was excavated using the discrete element method [10]. Cravero and Iabichino discussed the flexural failure of a gneiss slab from a quarry face by virtue of linear elastic fracture mechanics (LEFM), finite element method (FEM) [11], and so forth [12-14].

In summary, though many research achievements have been made, the results that the rock plate was supposed to be the thin plate or beam were lacking laboratory test to be verified. In addition, some numerical calculations were based on the continuum mechanics, which could not reflect the spatial heterogeneity and the anisotropic effect of the roof in the mining field. Only a few researchers utilized the discrete element methods to study the macromechanical response of the rock plate and did not further explore the microscopic damage of the rock plate. Therefore, a new loading device was developed to study the rock-arch instability characteristics of the plate, and particle flow code was used to further probe into the microscopic damage of the rock plate under the concentrated and the uniform loading, respectively.

\section{Loading Experiment of Rock Plate}

2.1. Sample of Rock Plate. The rock plate samples in the test were Hawkesbury sandstone, obtained from Gosford Quarry in Sydney, Australia. The quartz sandstones were formed in marine sedimentary basin of the Mid-Triassic and located on the top of the coal-bearing strata, which contained a small quantity of feldspars, siderite, and clay minerals. The surface of the specimen exhibited local red rather than usual white because of the content and distribution of the iron oxide. According to the definition of the thin plate and thick plate in elastic mechanics, the specimen size of the thick plate was designed to be $190 \mathrm{~mm} \times 75 \mathrm{~mm} \times 24 \mathrm{~mm}$ (length, width, and thickness) and that of the thin plate was designed to be $190 \mathrm{~mm} \times 75 \mathrm{~mm} \times 14 \mathrm{~mm}$ (length, width, and thickness). Each kind of rock plate was prepared for at least three plates.

2.2. Loading Equipment. The MTS-851 rock mechanics testing machine was selected as loading equipment, the load was controlled by vertical displacement, and loading rate was set $1 \times 10^{-2} \mathrm{~mm} / \mathrm{s}$ [15]. The vertical force and displacement occurring in the process of test were automatically recorded in real time by data acquisition system.

As shown in Figure 1, the concentrated and the uniform loading test sets were designed to mainly consist of three parts. The top was a point loading for the concentrated loading or an assembly of the steel balls for the uniform loading. The middle was loading framework which included four bolts with nuts connecting the steel plates on both sides, and the lateral pressure cell was placed between the deformable steel plate and the thick steel plate so as to monitor the horizontal force. The capacity of the lateral pressure cell LPX was $1000 \mathrm{~kg}$. The bottom was a rectangle steel foundation, and the rotatable hinge supports were set on both sides of the loading framework to maintain connection with the steel plates.
2.3. Acoustic Equipment and Data Acquisition System. In order to monitor the cracks initiate and identify the failure location of the rock plate, and the USB AE nodes were used in the test. The USB AE node is a single channel acoustic emission (AE) digital signal processor with full AE hit and time based features. In the test there were four USB AE nodes being connected to a USB hub for multichannel operation (Figure 2). All these AE nodes were made in MISTRAS Group, Inc., USA.

\section{Experiment Results and Analysis}

3.1. Characteristic of Force-Displacement Curve. As shown in Figure 3, the vertical force-displacement curves appeared two peaks under both the concentrated loading and the uniform loading, and the second peak value is higher than the first one. The thin rock plate showed the similarity cases in the test with the thick plate; only the peak values of the vertical and the horizontal force were lower than that of the thick one. In general, the curves of the force-displacement could be classified as four mechanical response stages as follows (Figure 1(a)).

Stage One. The rock plate was in the small deformation elastic stage. With the vertical force slowly increasing, the vertical displacement grew gradually. On the contrary, the horizontal force showed the slight decrease, which was mainly caused by the slight horizontal shrink of the rock plate during the loading process.

Stage Two. The rock plate produced brittle rupture and formed the rock-arch structure. As the vertical displacement went to about $2.5 \mathrm{~mm}$, the vertical force appeared with abrupt increase firstly and then dropped sharply in a small interval, which indicated the rock plate producing brittle rupture. Subsequently, the rock-arch structure was formed under the vertical and the horizontal reaction forces, and the horizontal force started to increase.

Stage Three. The rock-arch structure began to bear loads and produced deformation. With the vertical force increasing, the middle hinge point of the rock-arch structure moved down, and the two flanks of the rock-arch rotated around the hinge point, respectively. Such kinds of motion would stretch the rock-arch structure in the horizontal direction and squeeze the plate in two sides, and the horizontal force showed a significant growth.

Stage Four. The instability of the hinged rock-arch structure happened. With the vertical force continuously increasing, the middle hinged point of the rock-arch structure moved down constantly, and when the hinged point exceeded the horizontal line formed by the hinged point and two ends of the plate, the rock-arch structure went into instability thoroughly.

Under the uniform loading, the damage and fracture extent of the rock plate was more serious than that under the concentrated loading, especially at the two ends of the 


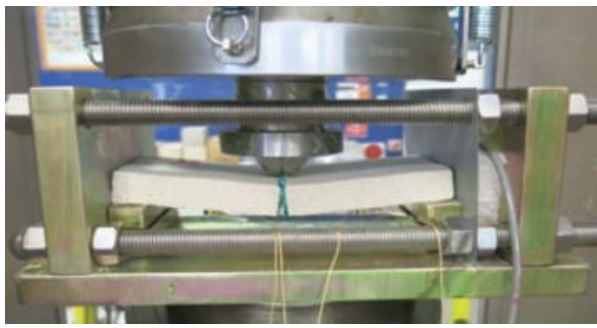

(a) Concentrated loading

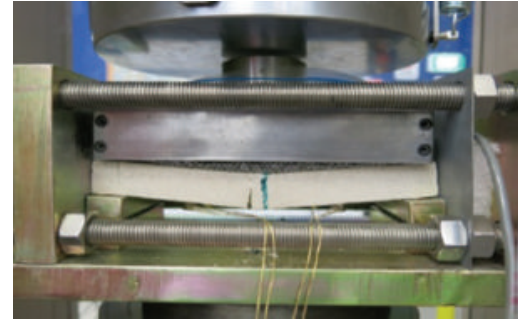

(b) Uniform loading

FIgURE 1: Loading experiment for rock plate.

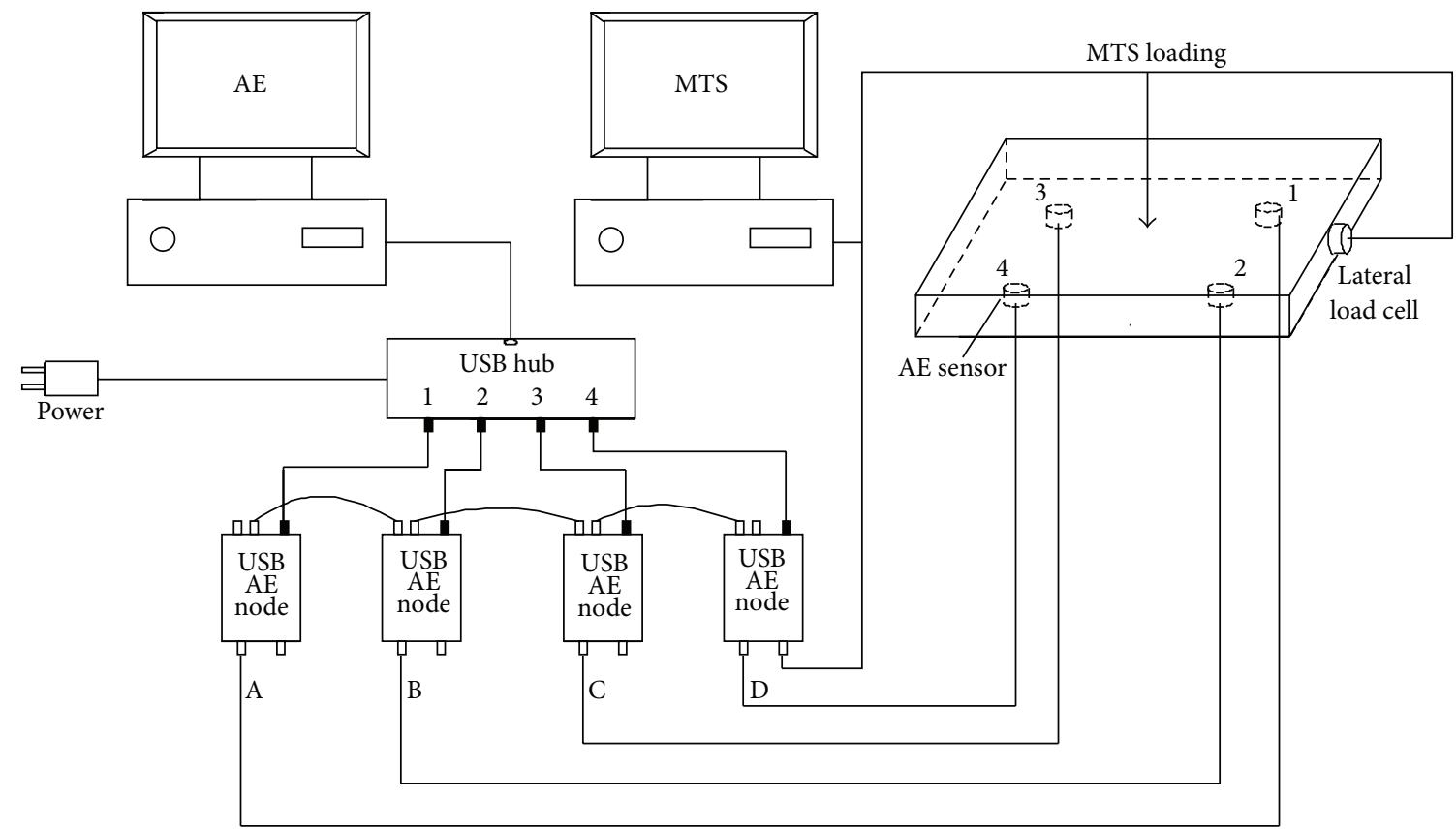

FIGURE 2: MTS connection with AE monitoring system diagram.

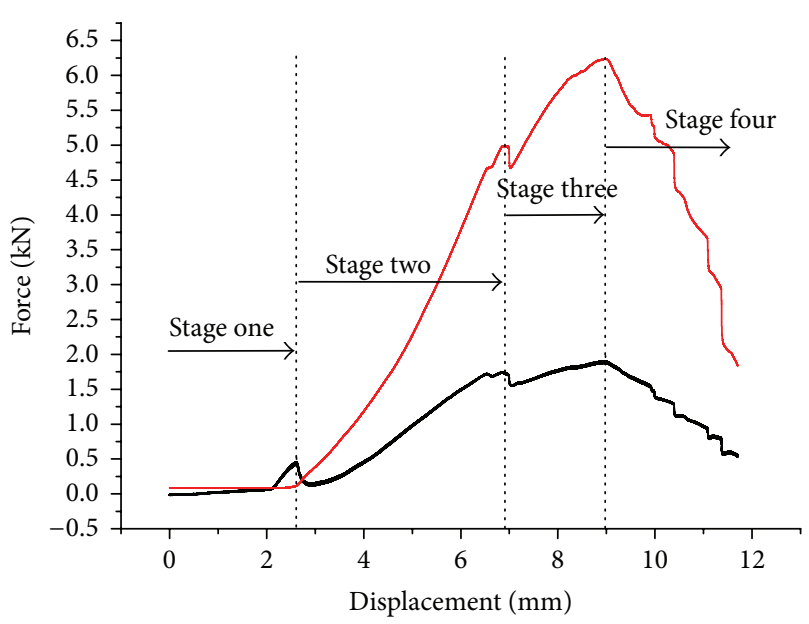

_ Vertical force

- Horizontal force

(a) Concentrated loading

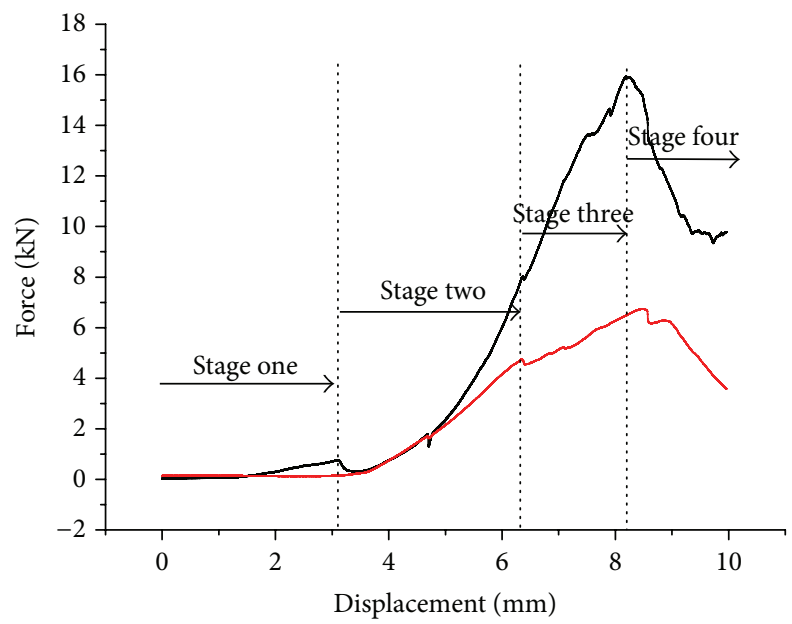

- Vertical force

— Horizontal force

FIGURE 3: Force-displacement curves under different loading conditions. 


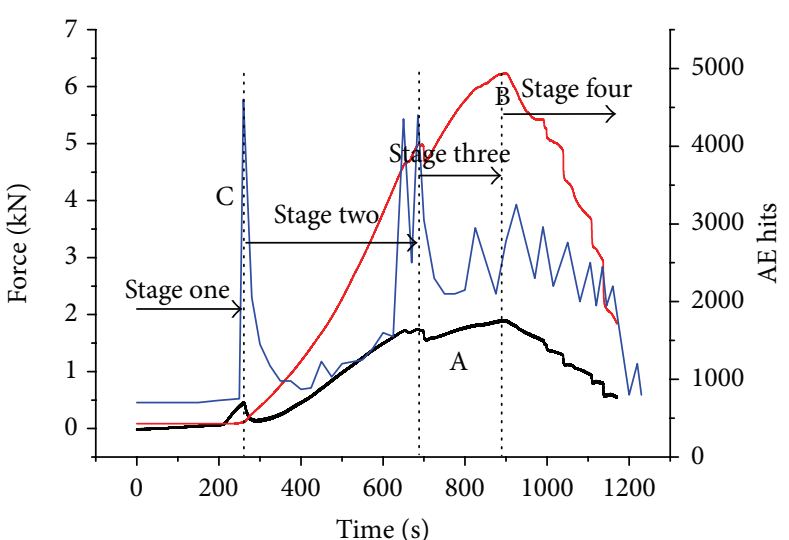

A, vertical force
_ B, lateral force
C, AE hits

(a) Concentrated loading

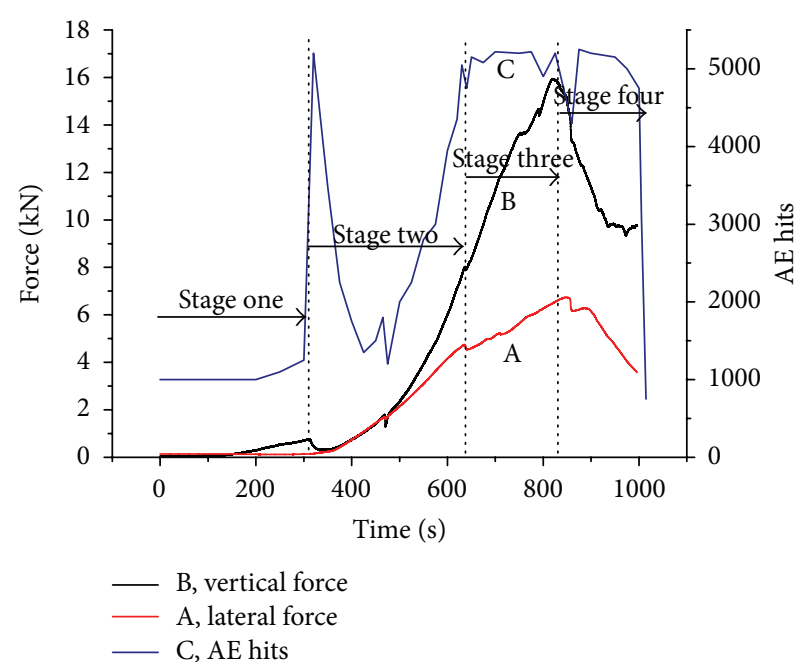

(b) Uniform loading

Figure 4: AE hits and force-displacement curves under different loading conditions.

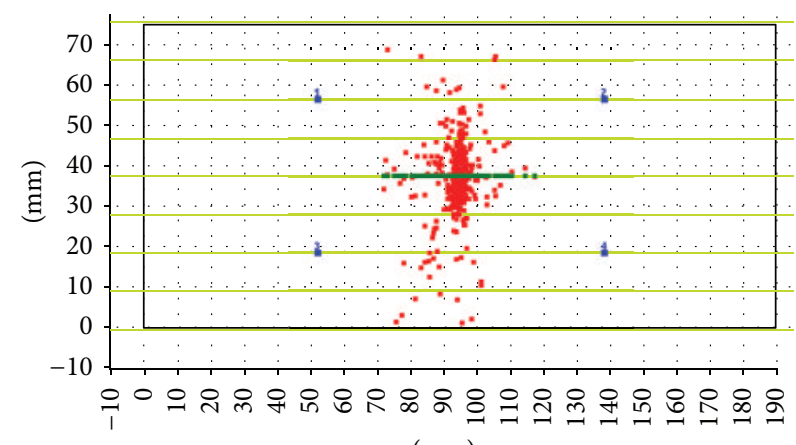

$(\mathrm{mm})$

(a) Initial crack

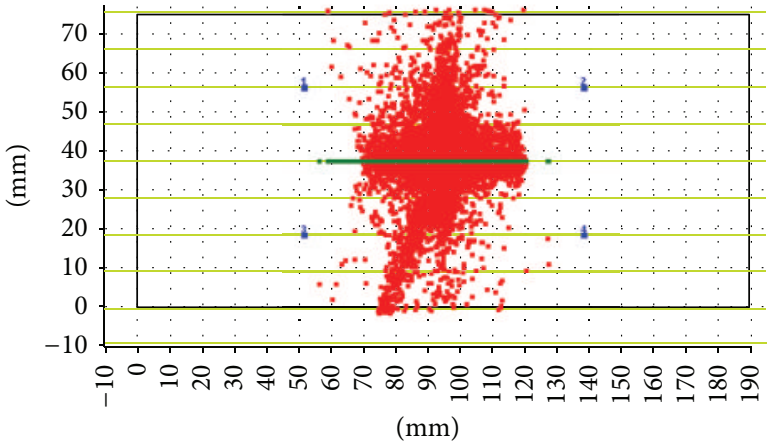

(b) Ultimate cracks

FIGURE 5: AE location of rock plate under concentrated loading.

rock plate (Figure 1(b)). As shown in Figure 3, the loaddisplacement curve showed similarity with the concentrated loading, and the peak value of the vertical force was greater than that under the concentrated loading, while the maximum value of the horizontal force showed basically the same (about $6.2 \mathrm{kN}$ ) with each other.

3.2. Acoustic Characteristic in the Process of the Rock Plate Failure. As shown in Figure 4, in the beginning of stage two, the $\mathrm{AE}$ hits under the uniform loading were greater than that under the concentrated loading, which were about 5000 and 4500, respectively. In stage three and stage four, the AE hits were also greater and more evenly distributed under the uniform loading compared with the concentrated loading, which were about 5000 and 3000, respectively.

As shown in AE location map (Figures 5 and 6), the results showed obvious differences in the initial crack position and the cracks distribution of the rock plate under different loading conditions. When the rock-arch structure went into instability, the differences in the damage extent and scope between the two loading methods were shown. All in all, the results of AE hits and location showed that the over damage extent and scope of the rock plate caused by the uniform loading were more serious than that under the concentrated loading condition.

\section{Numerical Simulations of the Loading Test of the Rock Plate}

4.1. Parameters Calibration of the Rock Plate. The rock plate was treated as the porous and solid material that consisted of particles and cement bodies. The force-displacement curve was simulated under the concentrated loading using the $\mathrm{PFC}^{3 \mathrm{D}}$.

Before the numerical simulation model being built, the microparameters needed to be adjusted repeatedly and finalized until the macromechanical parameters calculated were consistent with the physical macromechanical parameters [16]. 


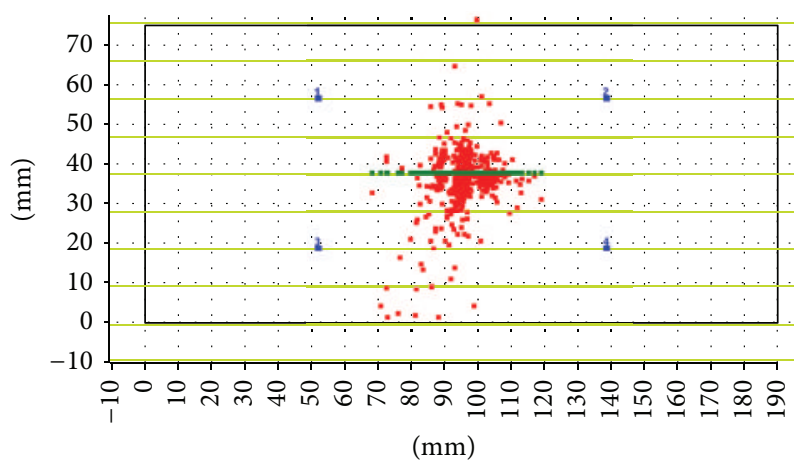

(a) Initial crack

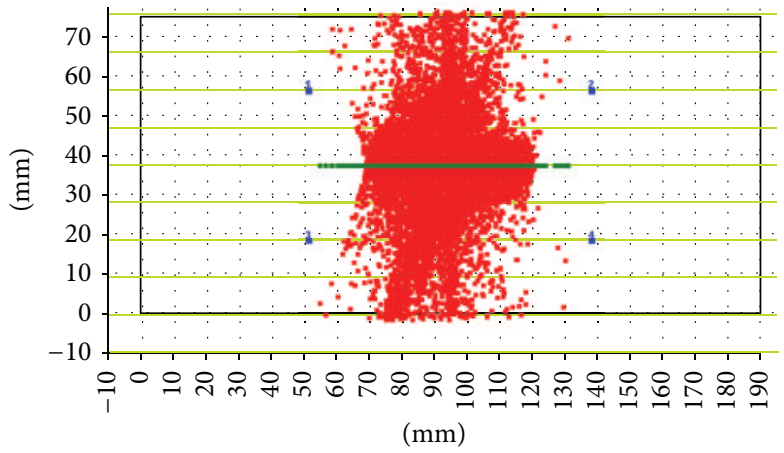

(b) Ultimate cracks

FIGURE 6: AE location of rock plate under uniform loading.

TABLE 1: Microparameters of the model in $\mathrm{PFC}^{3 \mathrm{D}}$.

\begin{tabular}{llccccccccc}
\hline$\rho / \mathrm{kg} / \mathrm{m}^{3}$ & $R_{\min } / \mathrm{m}$ & $R_{\text {ratio }}$ & $\mu$ & $\bar{\lambda}$ & $E_{c} / \mathrm{Pa}$ & $\bar{E}_{c} / \mathrm{Pa}$ & $k_{n} / k_{s}$ & $\bar{k}_{n} / \bar{k}_{s}$ & $\bar{\sigma}_{c} / \mathrm{Pa}$ & $\bar{\tau}_{c} / \mathrm{Pa}$ \\
\hline 2650 & $1.2 e-3$ & 1.66 & 0.5 & 1.0 & $2.7 \mathrm{e} 9$ & $2.8 \mathrm{e} 9$ & 1.8 & 1.8 & $16 \mathrm{e} 6$ & $16 \mathrm{e} 6$ \\
\hline
\end{tabular}

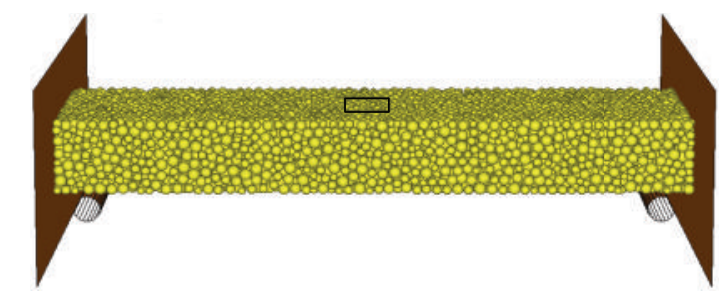

Figure 7: Computational model and its boundaries.

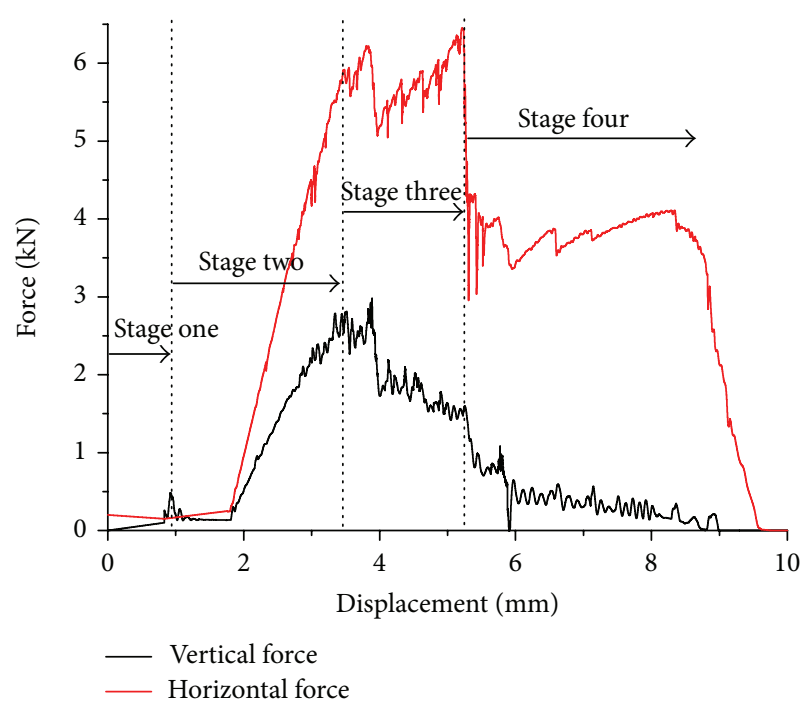

FIGURE 8: Force-displacement relationship curves.

The microparameters required to be adjusted were as follows: $\rho$ is ball density, $R_{\min }$ is minimum ball radius, $R_{\text {ratio }}$ is ratio of the largest to the smallest radii, $\bar{\lambda}$ is parallelbond radius multiplier, $E_{c}$ is ball-ball contact modulus, $\bar{E}_{c}$ is parallel-bond modulus, $k_{n} / k_{s}$ is ball stiffness ratio, $\bar{k}_{n} / \bar{k}_{s}$ is parallel-bond stiffness ratio, $\mu$ is ball friction coefficient, $\bar{\sigma}_{c}$ is parallel-bond normal strength, and $\bar{\tau}_{c}$ is parallel-bond shear strength. The microparameters required to be adjusted were listed in Table 1.

4.2. Building the Computational Model. The thick plate of $190 \mathrm{~mm} \times 75 \mathrm{~mm} \times 24 \mathrm{~mm}$ (length, width, and thickness) was taken as an example to show how to build the numerical calculation model.

Firstly, a parallelepiped specimen consisting of arbitrary particles confined by six frictionless walls was generated by the radius expansion method. Secondly, the radii of all particles were changed uniformly to achieve a specified isotropic stress so as to reduce the magnitude of lockedin stresses that would develop after the subsequent bond installation. In this paper the isotropic stress was set to $0.1 \mathrm{MPa}$. Thirdly, the floating particles that had less than three contacts were eliminated. Fourthly, the parallel bonds were installed throughout the assembly between all particles that were in near proximity to finalize the specimen. Lastly, the loading devices were installed on the rock plate as shown in Figure 7.

A square wall with sides of $10 \mathrm{~mm}$ was made on the top of the rock plate as the concentrated loading, and the loading rate was set to $0.01 \mathrm{~m} / \mathrm{s}$ (the loading rate could be regarded as the quasistatic loading). The two cylinder walls were placed on the right and left at the bottom, respectively, as supporting base. The two walls located in both sides could install the initial horizontal force at the specified value. During the loading, the cracks generated in the rock plate were monitored in real time. The red cracks represented the tensile fracture, and the black ones represented the shear fracture.

4.3. Analysis of the Numerical Simulation Results. As shown in Figure 8, since the interaction forces among the particles 


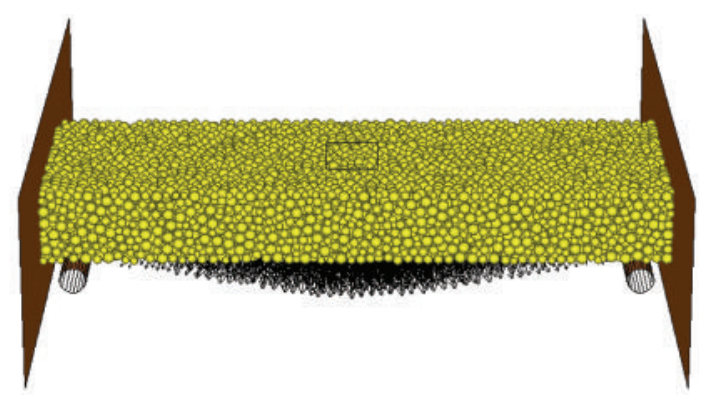

(a) Elastic stage

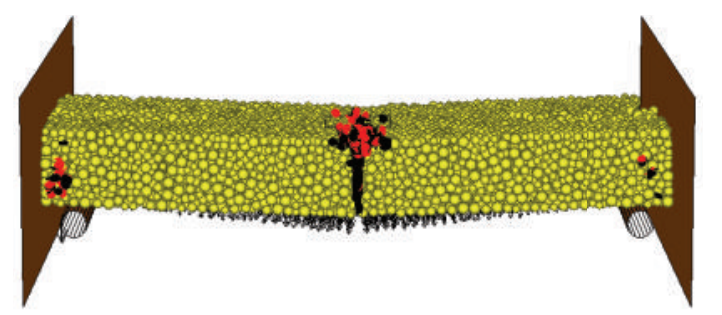

(c) Bearing loading stage

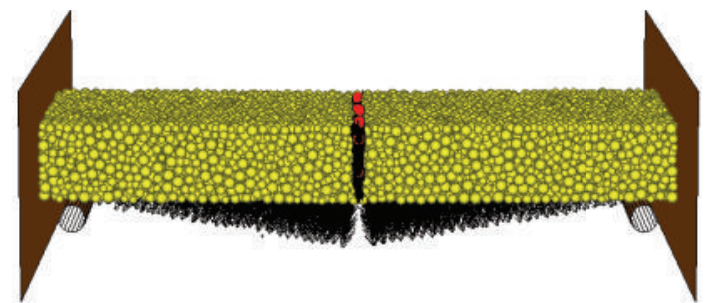

(b) Brittle rupture stage

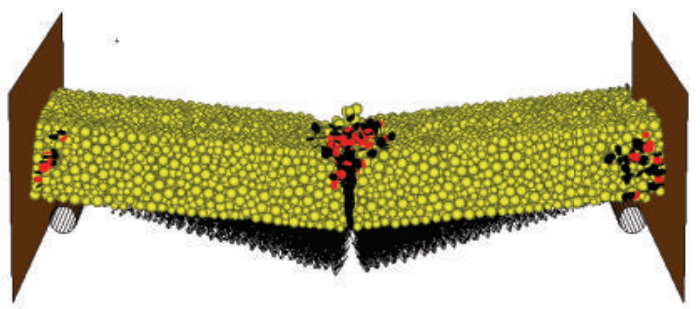

(d) Rock-arch instability stage

FIGURE 9: Rock-arch instability process under the concentrated loading.

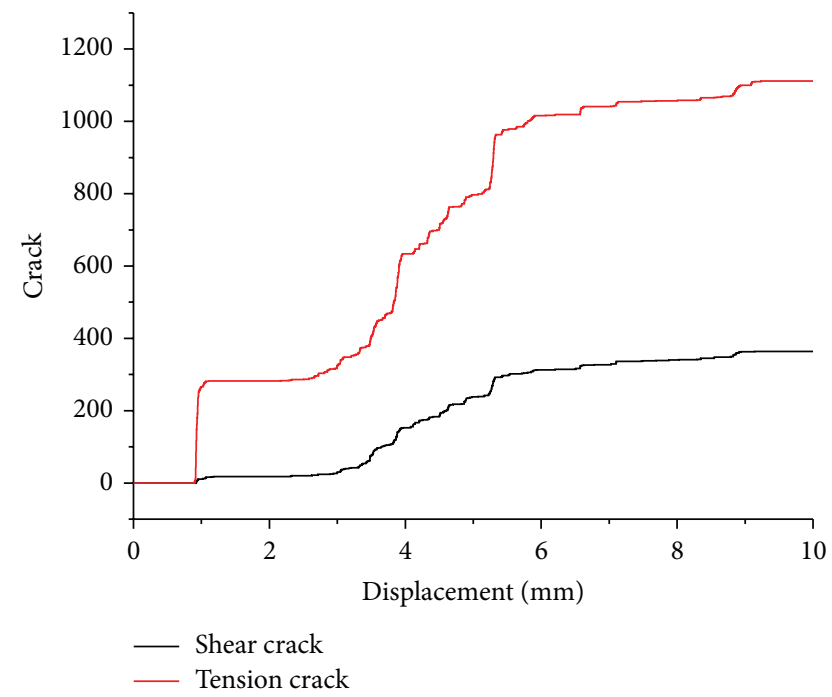

FIgURE 10: Crack-displacement curves.

were simplified in $\mathrm{PFC}^{3 \mathrm{D}}$, there were some differences in the vertical force-horizontal force-displacement simulated curves compared with the physical experimental curves, but the variation trend of the curves was basically the same for two cases, so the physical experimental results confirmed the numerical credibility.

In the elastic deformation stage (Figure 9(a)), the displacement vector field described that a slight elastic deformation was produced in the rock plate and at the same time there was no crack generated in this stage. In the brittle rupture stage (Figure 9(b)), there were many tensile cracks produced in the rock plate, and these tensile cracks formed a tensile failure plane in the rock plate. In the rock-arch bearing load

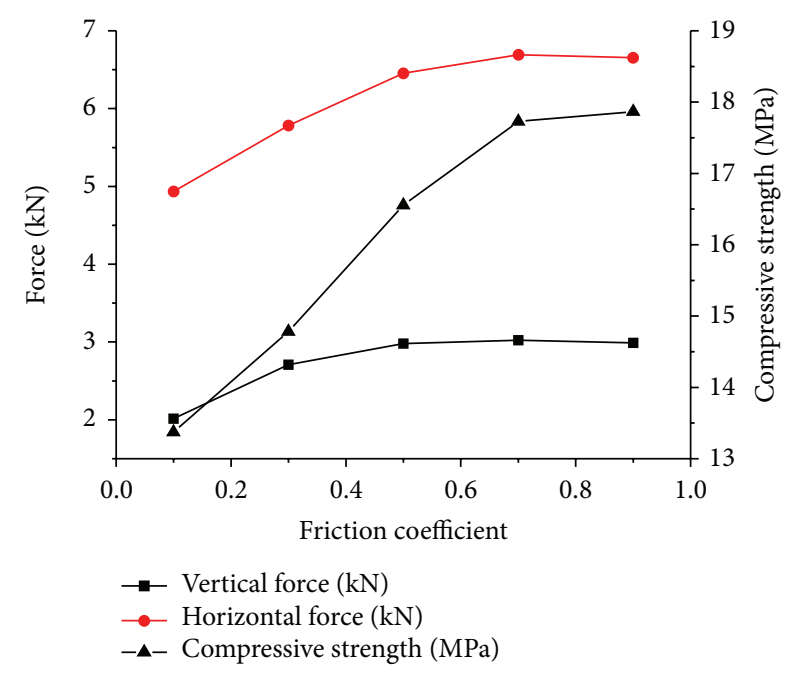

FIgURE 11: Force-friction coefficient curves.

stage (Figure 9(c)), there were the shearing and tension cracks emerging in the hinged plane and both ends of the rock plate. In the rock-arch instability stage (Figure $9(\mathrm{~d})$ ), the rock-arch structure had a large deformation, and parts of the particles in the hinged plane of both sides had escaped from the rock plate mainly due to the squeezing fracture.

As shown in Figure 10, the number of shear cracks obeyed the S-figure curve during the whole mechanical response process, which was also applicable to the tensile cracks only after the brittle rupture. When the vertical displacement reached around $1.0 \mathrm{~mm}$, the number of the tensile cracks surged to 300 . As the displacement varied in the interval $1.0-2.5 \mathrm{~mm}$, the crack development kept almost unchanged. However, with the displacement continuously increasing, the number 


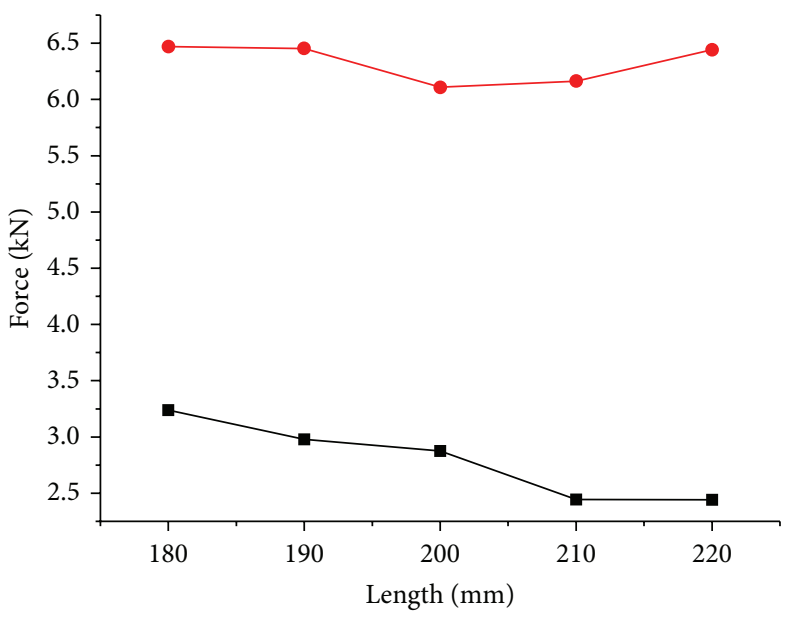

(a) Length effect

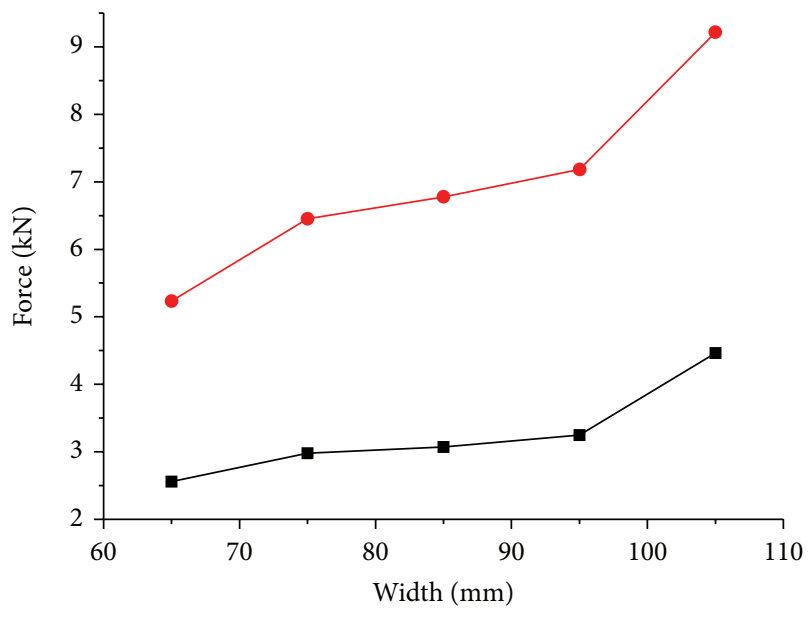

(b) Width effect

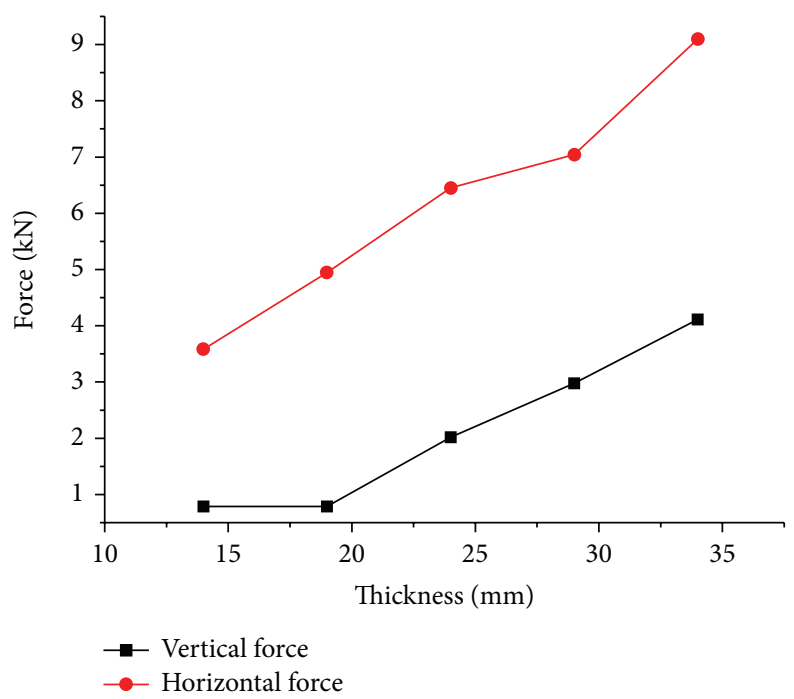

(c) Thickness effect

FIGURE 12: The forces variation with the rock plate geometry parameters.

of both shearing and tension cracks kept increasing, the hinged planes and both ends of the rock plate showed the mixture of shearing and tensile cracks. As rock-arch structure went into instability, the number of cracks still kept significant increase until the displacement reached $6 \mathrm{~mm}$.

\section{Sensitive Analysis of Influence Factors of the Rock-Arch Instability}

5.1. Material Parameter Effect. As shown in Figure 11, with the friction coefficient of the particles increasing, the peak values of the vertical force and the horizontal force of the rock-arch structure also increased. This was mainly because the friction growth enhanced the peak strength of the rock material; namely, after breakage of the parallel bond, the strength of the rock material was often contributed by the contact friction of the particles.
5.2. Geometry Size Effect. As shown in Figure 12, the length, width, and thickness of the rock plate were changed, respectively, to reveal the size effect on the instability of the rock-arch structure. With the length of the rock plate increasing, the peak values of the vertical and the horizontal force were gradually decreased, and the whole variation interval was small. With the width and the thickness of the rock plate increasing, the peak values of the vertical and the horizontal force showed obvious growth. In short, the response of the rock-arch structure instability was more sensitive to the width and thickness compared with the length.

5.3. Loading Rate and Initial Horizontal Force Effect. As shown in Figure 13(a), when the loading rate exceeded $10 \mathrm{~mm} / \mathrm{s}$, with the loading rate increasing, the peak values of the vertical and the horizontal force showed the linear growth trend, and the amplitude of that variation was small. 


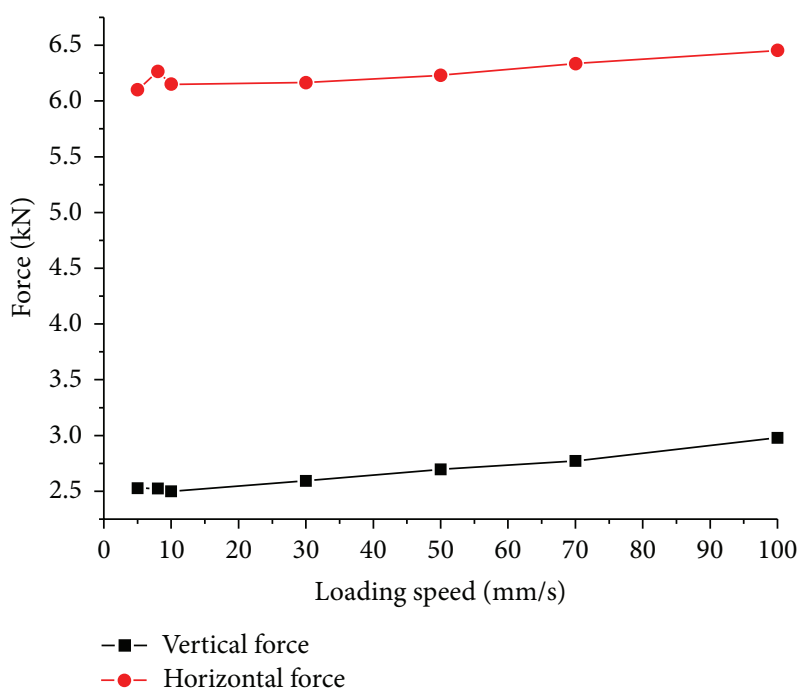

(a) Loading speed effect



(b) Initial horizontal force

FIGURE 13: Forces versus the loading speed and the initial horizontal force.

When the loading rate was in the interval of $1.0 \mathrm{~mm} / \mathrm{s} \sim$ $10 \mathrm{~mm} / \mathrm{s}$, the peak values were almost unchanged; therefore, such loading rate could be regarded as the quasistatic loading.

As shown in Figure 13(b), when the initial horizontal force was less than $2.0 \mathrm{kN}$, with the initial horizontal force increasing, the vertical and the horizontal force of the rock plate showed the nonlinear fluctuating growth trend. When the initial horizontal force was larger than $2.0 \mathrm{kN}$, with the initial horizontal force increasing, the vertical and the horizontal force would show the linear growth trend.

\section{Conclusions}

Under the concentrated and the uniform loading, there were the elastic deformation, brittle rupture, rock-arch bearing load, and rock-arch instability four stages in the forcedisplacement curves. The peak value of the vertical force under uniform loading was greater than that under the concentrated loading. The number of AE hits and AE location showed that the damage extent and scope of the rock plate under the uniform loading were greater than that under the concentrated loading.

The simulation results showed that the tensile cracks of the rock plate were dominating during the concentrated loading. The numerical test results showed that the instability of the rock-arch structure was more sensitive to the width and thickness compared with the length. The loading rate could be regarded as the quasistatic loading when it was less than $10 \mathrm{~mm} / \mathrm{s}$. The vertical and the horizontal force would show the growth trend with the initial horizontal force increasing.

In order to obtain the more precise simulation results in calculation by using $\mathrm{PFC}^{3 \mathrm{D}}$ compared with the physical experimental results, the more precise description for the numerical model and the interaction forces among the particles should be improved.

\section{Conflict of Interests}

The authors declare that there is no conflict of interests regarding the publication of this paper.

\section{Acknowledgments}

This work was financially supported by the National Natural Science Foundation of China (51074140; 51310105020), the Natural Science Foundation of Hebei Province of China (E2014203012), and Program for Taihang Scholars; all these are gratefully acknowledged.

\section{References}

[1] H. Wang, Z. Chen, Z. Du, and J. Li, "Application of elastic thin plate theory to change rule of roof in underground stope," Chinese Journal of Rock Mechanics and Engineering, vol. 25, no. 2, pp. 3769-3774, 2006.

[2] J.-A. Wang, X.-C. Shang, H. Liu, and Z.-Y. Hou, "Study on fracture mechanism and catastrophic collapse of strong roof strata above the mined area," Journal of the China Coal Society, vol. 33, no. 8, pp. 849-855, 2008.

[3] S. R. Wang and H. H. Jia, "Analysis of creep characteristics of shallow mined-out areas roof under low stress conditions," Applied Mechanics and Materials, vol. 105-107, pp. 832-836, 2012.

[4] J.-A. Wang, X. C. Shang, and H. T. Ma, "Investigation of catastrophic ground collapse in Xingtai gypsum mines in China," International Journal of Rock Mechanics and Mining Sciences, vol. 45, no. 8, pp. 1480-1499, 2008.

[5] Y. Pan, S. T. Gu, and Y. S. Qi, "Analytic solution of tight roof's bending moment, deflection and shear force under advanced super charger load and supporting resistance before first weighting," Chinese Journal of Rock Mechanics and Engineering, vol. 32, no. 8, pp. 1545-1553, 2013. 
[6] Y. Zhao, Q. Wu, W. Wang, W. Wan, and F. Zhao, "Strength reduction method to study stability of goaf overlapping roof based on catastrophe theory," Chinese Journal of Rock Mechanics and Engineering, vol. 29, no. 7, pp. 1424-1434, 2010.

[7] S. R. Wang, H. Wang, and B. W. Hu, "Analysis of catastrophe evolution characteristics of the stratified rock roof in shallow mined-out areas," Disaster Advances, vol. 6, no. 1, pp. 59-64, 2013.

[8] Z.-L. Wang, Y.-C. Li, and J. G. Wang, "Numerical analysis of blast-induced wave propagation and spalling damage in a rock plate," International Journal of Rock Mechanics and Mining Sciences, vol. 45, no. 4, pp. 600-608, 2008.

[9] P. P. Nomikos, A. I. Sofianos, and C. E. Tsoutrelis, "Structural response of vertically multi-jointed roof rock beams," International Journal of Rock Mechanics and Mining Sciences, vol. 39, no. 1, pp. 79-94, 2002.

[10] D. Bakun-Mazor, Y. H. Hatzor, and W. S. Dershowitz, "Modeling mechanical layering effects on stability of underground openings in jointed sedimentary rocks," International Journal of Rock Mechanics and Mining Sciences, vol. 46, no. 2, pp. 262-271, 2009.

[11] M. Cravero and G. Iabichino, "Analysis of the flexural failure of an overhanging rock slab," International Journal of Rock Mechanics and Mining Sciences, vol. 41, supplement 1, pp. 605610, 2004.

[12] S. R. Wang and M. S. Chang, "Reliability analysis of lining stability for hydraulic tunnel under internal water pressure," Disaster Advances, vol. 5, no. 4, pp. 166-170, 2012.

[13] J. F. Yin, S. R. Wang, Z. Q. Wang, J. M. Yu, and C. Cao, "Disturbance effects analysis of the coal pillar-roof system caused by a sudden instability coal pillar," Disaster Advances, vol. 6 , no. 13, pp. 29-37, 2013.

[14] J. H. Yang, S. R. Wang, C. L. Li, and Y. Li, "Disturbance deformation effect on the existing tunnel of asymmetric tunnels with small spacing," Disaster Advances, vol. 6, no. 13, pp. 269277, 2013.

[15] R. Ulusay and J. A. Hudson, The Complete ISRM Suggested Methods for Rock Characterization, Testing and Monitoring: 1974-2006, Kozan Ofset, Ankara, Turkey, 2007.

[16] D. O. Potyondy and P. A. Cundall, "A bonded-particle model for rock," International Journal of Rock Mechanics and Mining Sciences, vol. 41, no. 8, pp. 1329-1364, 2004. 

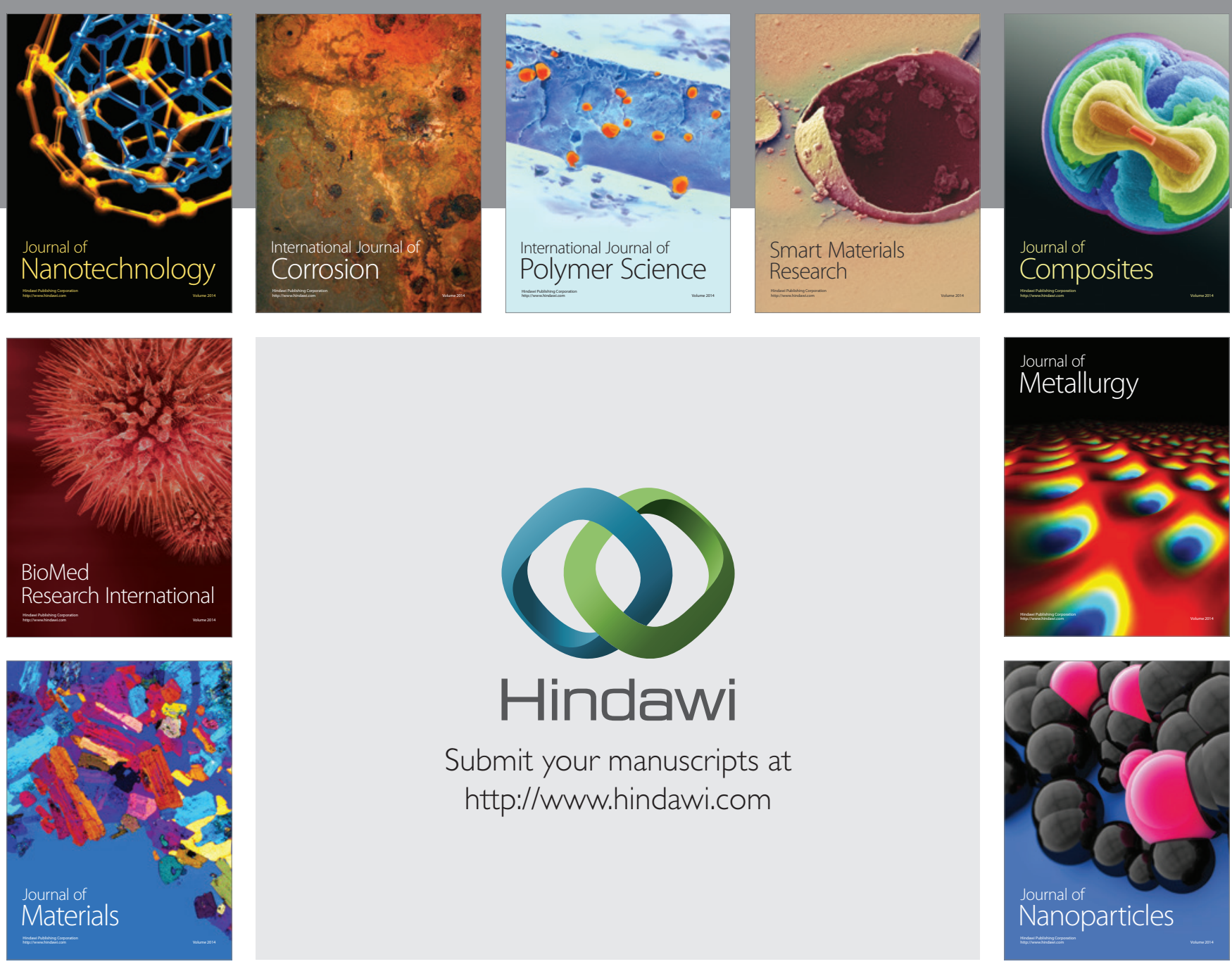

Submit your manuscripts at http://www.hindawi.com
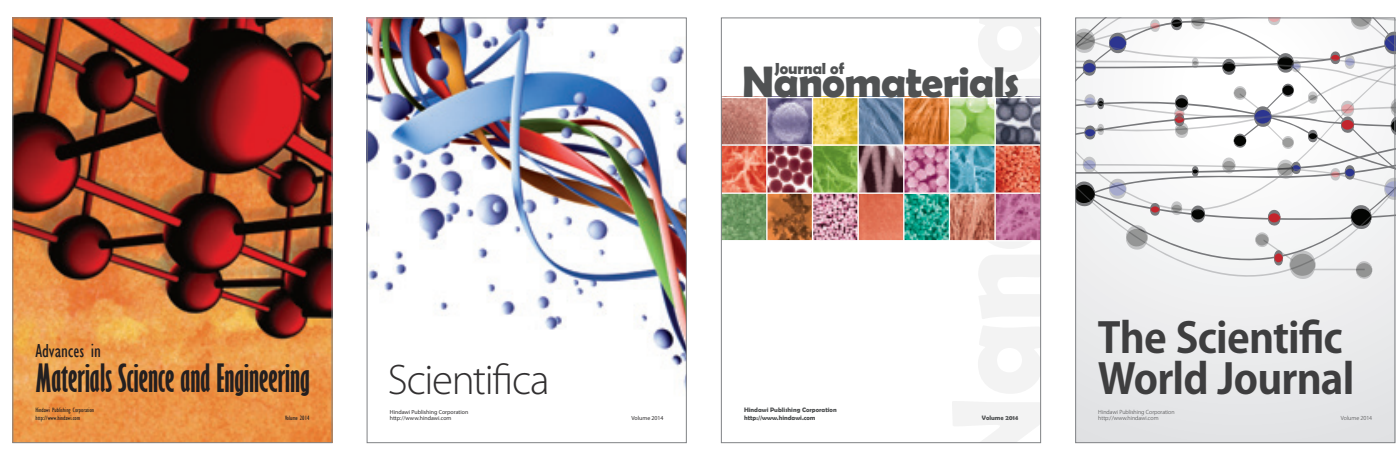

\section{The Scientific World Journal}
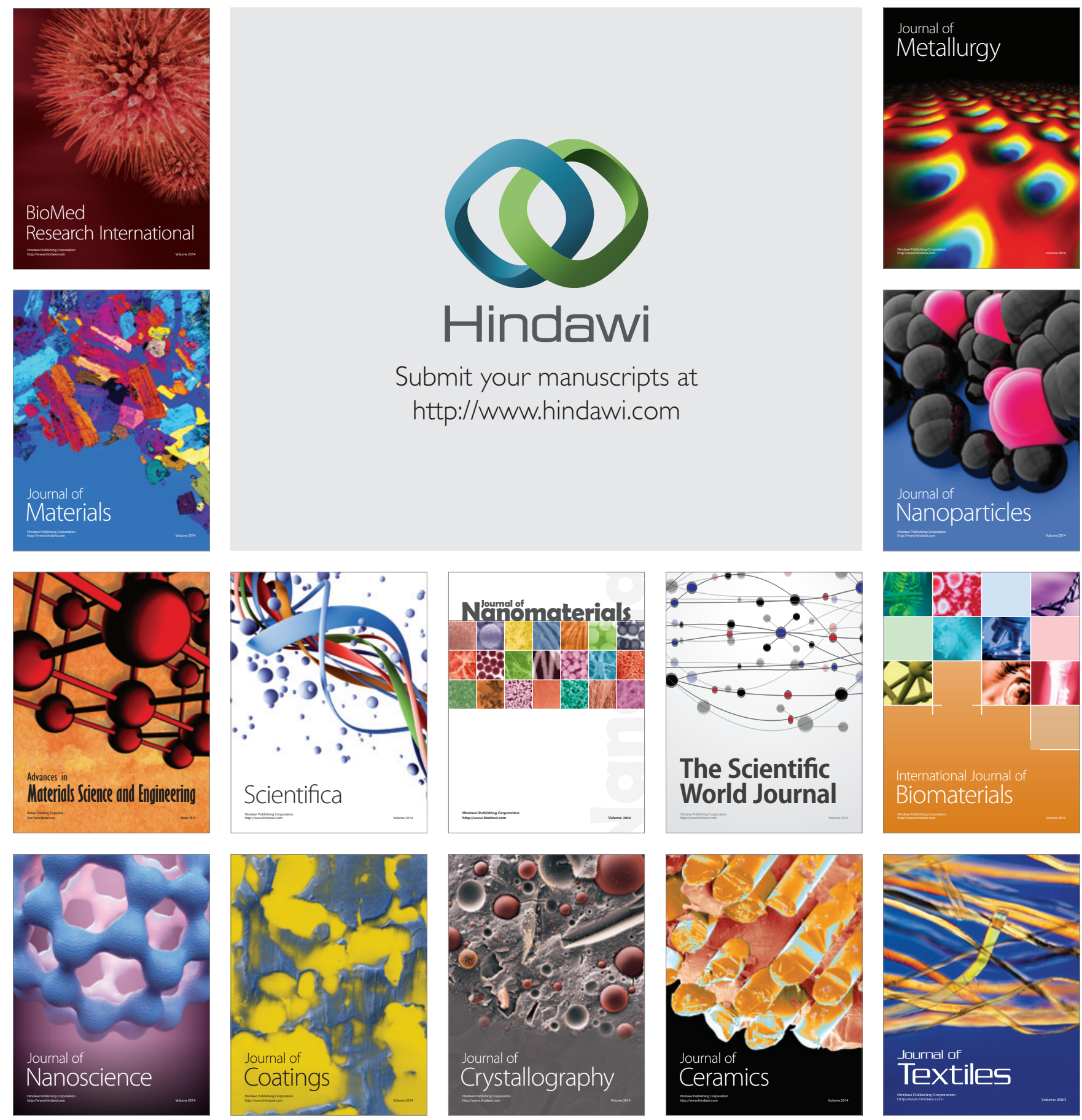